\title{
$630 \mathrm{~nm}$ nightglow observations from $17^{\circ} \mathrm{N}$ latitude
}

\author{
G. K. Mukherjee, L. Carlo, and S. H. Mahajan \\ Indian Institute of Geomagnetism, Dr. Nanabhai Moos Marg, Colaba, Mumbai 400 005, India
}

(Received October 6, 1997; Revised November 18, 1999; Accepted December 2, 1999)

\begin{abstract}
Regular measurements of [OI] $630 \mathrm{~nm}$ nightglow have been carried out at Kolhapur $\left(16.8^{\circ} \mathrm{N}, 74.2^{\circ} \mathrm{E}\right.$, dip lat $10.6^{\circ} \mathrm{N}$ ) in India with the help of tilting filter photometers during clear moonless nights. Several characteristic nightglow data sets are presented in the report for geomagnetically quiet and disturbed nights. A comparison has been made between the simultaneous nightglow and the ionospheric parameters of virtual $F$-layer height and critical frequency of the $F$-layer at Ahmedabad $\left(23.02^{\circ} \mathrm{N}, 72.6^{\circ} \mathrm{E}\right)$. In general, a good correlation (c.c. $=0.8$ to 0.9$)$ is found between the measured airglow emission and $F$-region peak electron densities during quiet periods but for intense magnetic disturbances the airglow fluctuations are mainly controlled by sharp changes in height variations of the $h^{\prime} F$ layer. The period of airglow variation generally corresponds to periods of $F$-region height variation during magnetic disturbances. Using a long series of data between December 1989 and April 1996, the mean seasonal nocturnal variations of $630 \mathrm{~nm}$ emission have been compared during high and low solar activity periods.
\end{abstract}

\section{Introduction}

A network of three tilting photometers developed by La Trobe University, Australia, has been installed at Kolhapur $\left(16.8^{\circ} \mathrm{N}, 74.2^{\circ} \mathrm{E}\right.$; dip lat $\left.10.6^{\circ} \mathrm{N}\right)$ in India to study the nighttime behaviour of the [OI] $630 \mathrm{~nm}$ emission line (Mukherjee and Dyson, 1992). Airglow from ionospheric structures observed by the photometer system acts as a tracer enabling the motions of these structures as well as intensity variations to be measured.

It is well known that [OI] $630 \mathrm{~nm}$ emission in the nighttime originates mostly from the bottomside of the $F$-region in low and middle latitudes by the dissociative recombination process given by $\mathrm{O}_{2}^{+}+\mathrm{e} \rightarrow O+O^{*}\left({ }^{1} \mathrm{~S},{ }^{1} \mathrm{D}\right) ; O^{*}\left({ }^{1} \mathrm{D}\right) \rightarrow O+$ $h v(630 \mathrm{~nm})$. The rate of this reaction is nearly proportional to the rate of recombination in the $F_{2}$ layer (Vanzandt and Peterson, 1968). The data sets presented and discussed here span from the period 1989 to 1996 which is of importance as it includes the transition from high to low solar activity.

In this paper we also report and discuss the several characteristic nightglow observations of $630 \mathrm{~nm}$ emission made at the low latitude station, Kolhapur, in India, on disturbed nights in comparison with their variations on quiet nights.

\section{Tilting Photometers}

The observations were made using a set of three tilting photometers. The tilting filter photometers have a one degree field of view (overall) giving a cross section of about 5 $\mathrm{km}$ in the $F$-region height $(250 \mathrm{~km})$ when looking at zenith. The interference filter (Barr Associates, U.S.A) when kept at a temperature of $23^{\circ} \mathrm{C}$ has a passband centered at about $630 \mathrm{~nm}$ for normally incident light. The band widths of the filters are about $1 \mathrm{~nm}$ with $60 \%$ transparency. The airglow

Copy right (C) The Society of Geomagnetism and Earth, Planetary and Space Sciences (SGEPSS); The Seismological Society of Japan; The Volcanological Society of Japan; The Geodetic Society of Japan; The Japanese Society for Planetary Sciences. intensity is determined from the difference of the background with signal and background only. The photometers are quite portable and can easily be mounted to point along any desired combination of zenith and azimuth angles. Hence horizontal motions in the thermosphere can be measured by pointing the photometers in three different directions. Typically one photometer is pointed to the zenith, second one to the north or south and third photometer is directed to the east or west.

\section{Nighttime Behaviour of $630 \mathrm{~nm}$ Emission dur- ing Magnetic Disturbance}

In this section we discuss the characteristic variations of $630 \mathrm{~nm}$ intensity observed during geomagnetically disturbed nights. For comparison with observations on magnetically disturbed nights, we present in Figs. 1(a) and (b) the observed [OI] $630 \mathrm{~nm}$ intensities on 25-26 and 27-28 January, 1995, which are magnetically quiet nights. To show the magnetic activity during the period of observations we indicate the activity index $A p$ also in Fig. 1. The $A p$ index is the diurnal average of three hour $A p$ indices which are the transformations of three hourly $K p$ index to a linear scale. Typical quiet time ( $A p=5$ and 4$)$ variations are shown for two nights in Figs. 1(a) and (b). We also plot in the same figure the hourly values of the ionospheric parameters (virtual height of the $F$ layer, $h F(\mathrm{~km})$ and square of the critical frequency of the $F_{2}$ layer $\left(f_{o} F_{2}\right)$ for the nearby station for the corresponding period. They were obtained from an ionosonde operating on a routine basis at Ahmedabad $\left(23.02^{\circ} \mathrm{N}\right.$, dip lat $\left.13.8^{\circ} \mathrm{N}\right)$ sited in the equatorial anomaly region. The square of the parameter $\left(f_{o} F_{2}\right)$ is proportional to the electron density at the peak of the $F_{2}$ layer (Moore and Weber, 1981). Note that there is a rapid fall in $630 \mathrm{~nm}$ intensity from 2100 hours to about middle of the night. This feature is common and seen also in the $\left(f_{o} F_{2}\right)^{2}$ variations at Ahmedabad. Figure 2 also depicts the comparison of the airglow intensity fluctuation with 

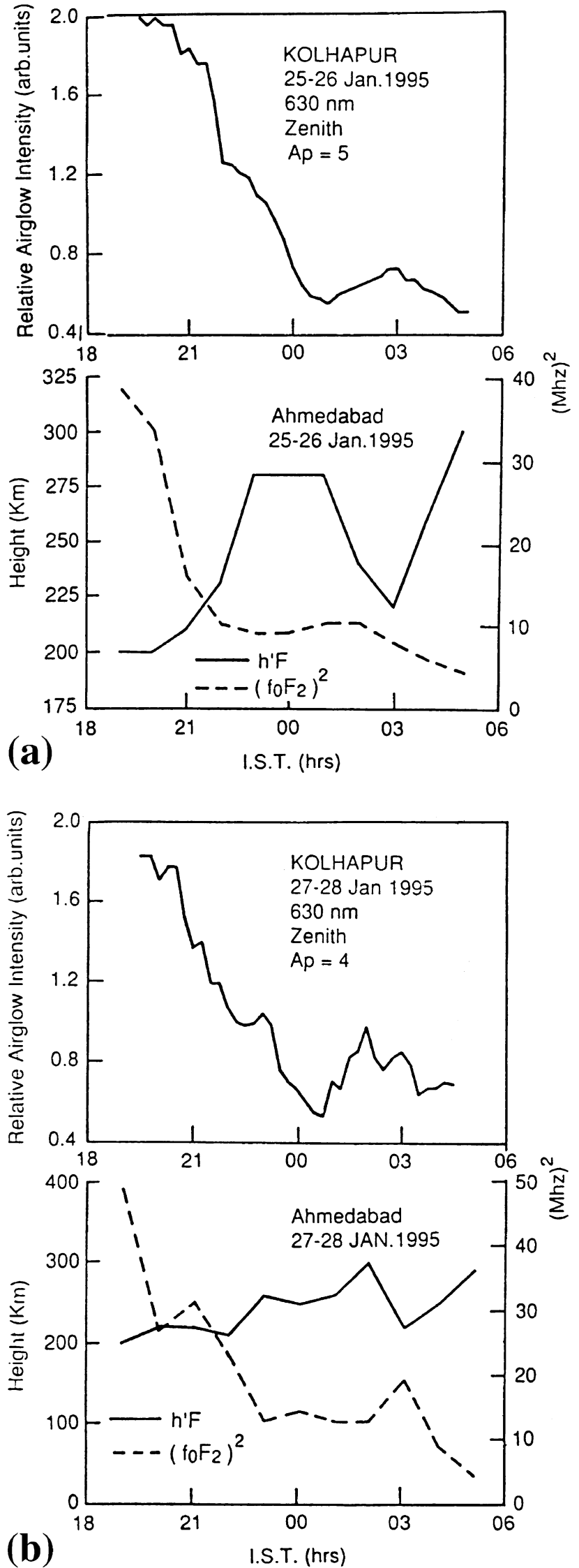

Fig. 1. (a), (b) Plot of the nightglow variations in [OI] $630.0 \mathrm{~nm}$ as a function of local time (IST) at Kolhapur for the two magnetically quiet nights of 25-26 and 27-28 January, 1985. The ionospheric parameters (virtual height of the $F$-layer $(h F(\mathrm{~km}))$ and critical frequency of the $F_{2}$-layer $\left.\left(f_{o} F_{2}\right)^{2}\right)$ are also depicted.

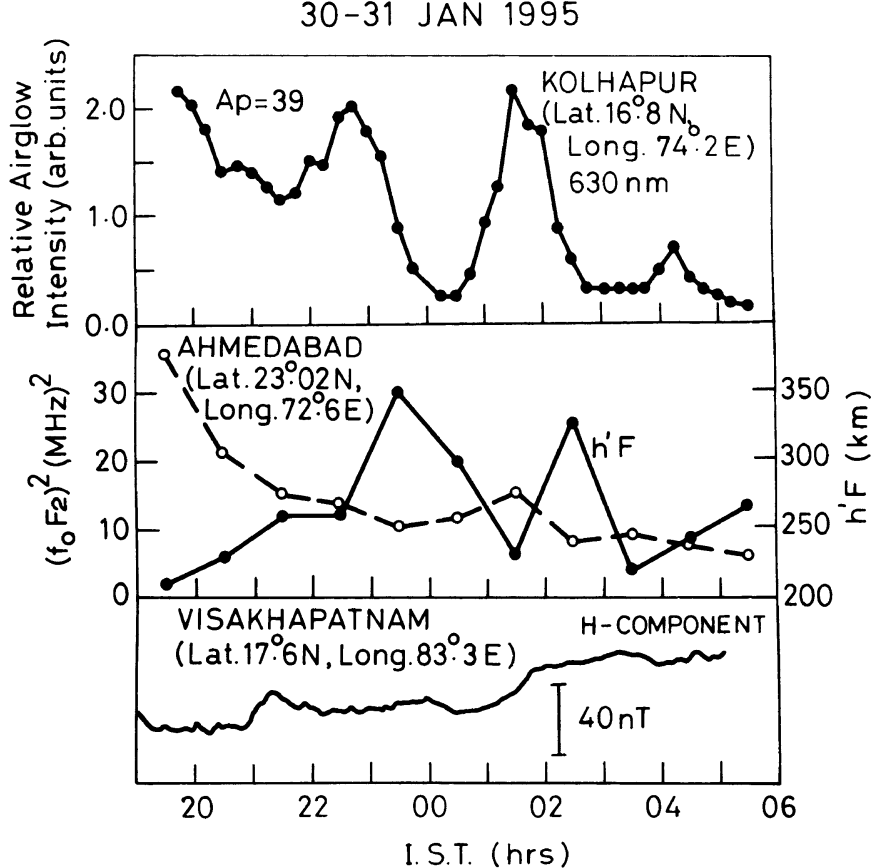

Fig. 2. Same as Fig. 1 but for the magnetically disturbed night of 30-31 January, 1995.

simultaneous ionosonde observations from Ahmedabad on a geomagnetically disturbed night on 30-31 January, 1995. It can be noted that the correlation between airglow intensity variation and $\left(f_{o} F_{2}\right)^{2}$ is poor. However, it shows good negative correlation (c.c. $=-0.89$ ) with the variation of the $F$-region height $\left(h^{\prime} F\right)$. The airglow data shows wavy disturbances which are also reflected in the height variations of the $h^{\prime} F$ layer. The dominant period (3 hours) of airglow fluctuation during the night also matches well with the periods of the height variation. Sahai et al. (1990) reported that the correlation coefficient between inverse of $630 \mathrm{~nm}$ intensity and $F$-region height were large for the disturbed nights as compared with quiet nights.

Figures 3 and 4 depict the $630 \mathrm{~nm}$ intensity variations observed at Kolhapur during the magnetically disturbed nights of 1-2 February and 2-3 February, 1992. The magnetic activity index $A p$ is also depicted in the figures. Dst and $K p$ indices are plotted in the lower panels. Two prominent peaks are noticed in Fig. 3 on February 1-2 around 2300 and $0300 \mathrm{hrs}$ IST with latter enhancement more in intensity than the former. The ionospheric data ( $h^{\prime} F$ and $f_{o} F_{2}$ values) from a nearby station, Ahmedabad, were compared for the corresponding nights. The hourly values of $h^{\prime} F$ and $\left(f_{o} F_{2}\right)^{2}$ parameters were used for the purpose and plotted in the same figure to find any significant correlation between ionospheric parameters and airglow intensity variations. It is noted that the $\left(f_{o} F_{2}\right)^{2}$ variation shows a wavy disturbance during the night and the enhancement of $630 \mathrm{~nm}$ intensity during 0100 to $0300 \mathrm{hrs}$ is accompanied by lowering of $F$-region heights at Ahmedabad. Figure 4 shows the sharper peak intensities in $630 \mathrm{~nm}$ intensity fluctuations with pronounced double peaks. Both the electron densities $\left(f_{o} F_{2}\right)^{2}$ and the $h^{\prime} F$ height variations show sharp fall and rise in their values during the 


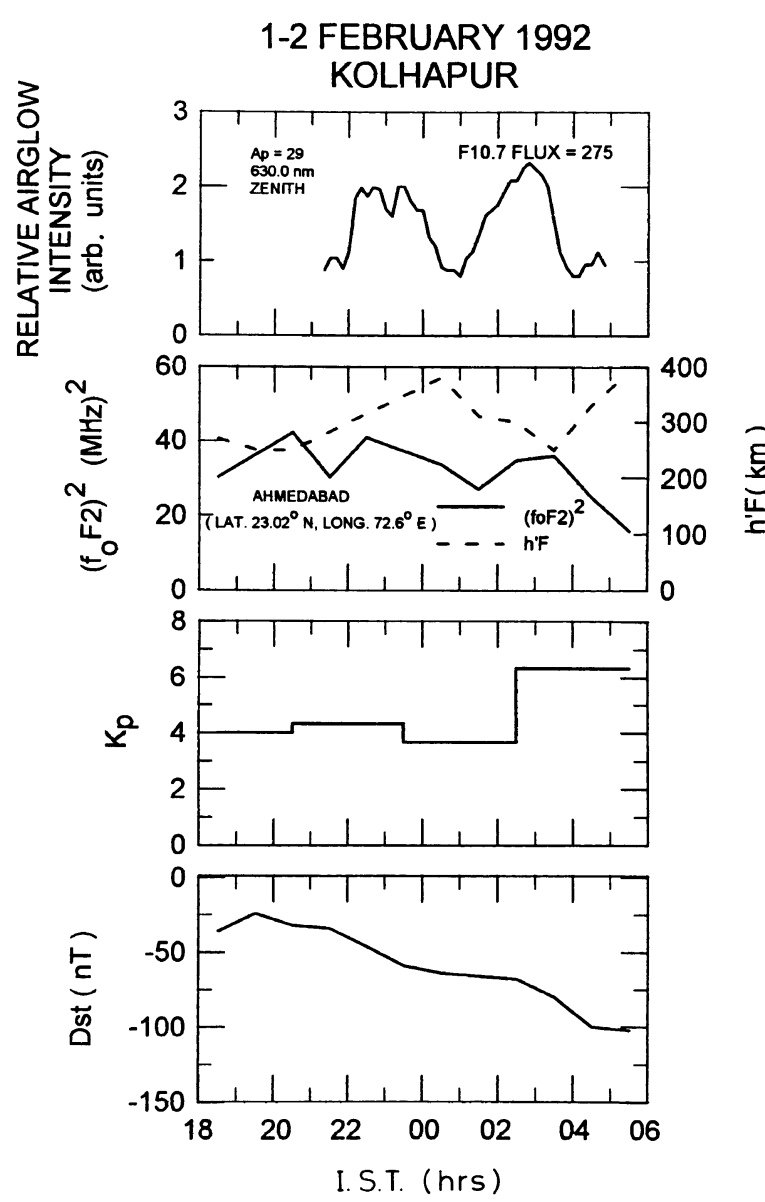

Fig. 3. Same as Fig. 2 but for another disturbed night of 1-2 February, 1992.

night. The airglow intensity variation shown in Fig. 4 (top) on February 2-3 brought out almost anticorrelation with $\left(f_{o} F_{2}\right)^{2}$ values and no correlation with the $h^{\prime} F$. The $h^{\prime} F$ values were low $(220 \mathrm{~km}$ to $250 \mathrm{~km})$ during the period of occurence of airglow peaks. The sharp fall in $630 \mathrm{~nm}$ intensity during post midnight hours after $0200 \mathrm{hrs}$ is followed by rapid rise in $h^{\prime} F$ height variation. This behaviour of the $630 \mathrm{~nm}$ emission on a disturbed night signifies the important role played by $F$-region dynamics. Such occurence of double maxima in $630 \mathrm{~nm}$ during magnetic disturbance has also been noted by Misawa and Takeuchi (1984) and Sahai et al. (1990) as shown in Fig. 1. Misawa and Takeuchi (1984) reported that on the nights of magnetic disturbance, large double maximum in the intensity of oxygen red line $(630 \mathrm{~nm})$ appeared and such intense double maxima have not appeared on magnetically quiet nights.

The observed ionospheric height variations (both positive and negative effect) at low latitudes during magnetic storms are dependent on factors like changes in dynamics, heating and composition of the ionosphere which take place depending upon latitude, longitude, local time and on the phase of the geomagnetic storm (Rishbeth et al., 1985). The electron concentration at low latitudes may vary drastically during magnetic storms. The perturbations of $\pm 50 \%$ from the quiet time densities are usually enhanced at low latitudes during geomagnetic disturbances, while the height of the
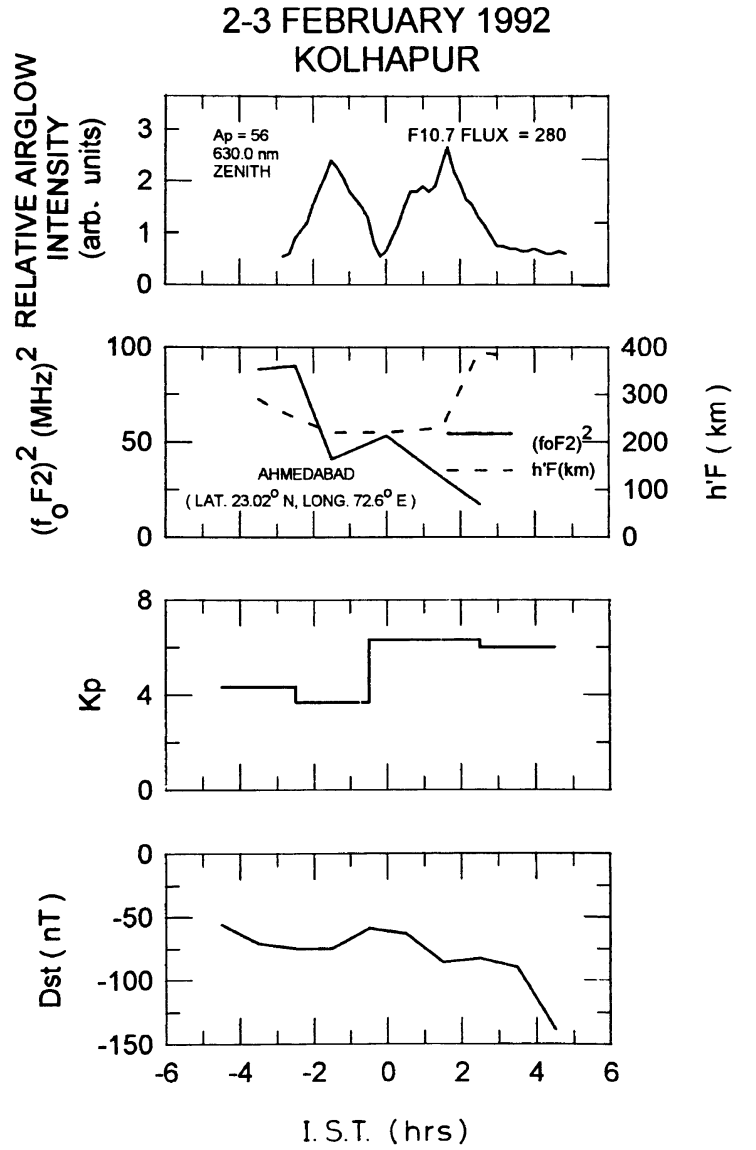

Fig. 4. Same as Fig. 2 but for 2-3 February, 1992.

$F$-layer typically increases a few tens of kilometres. During severe magnetic storms, however, decreases in electron density may occur at all latitudes. Rishbeth et al. (1985) reported that in general, the equatorial anomaly is less developed during storm periods. However, there are cases when the enhancements are strongly manifested in the crest region and the critical frequency in the equatorial trough is reduced compared to quiet days. Takahashi et al. (1987) have reported ionization enhancements at low latitudes during disturbed conditions. They showed that these enhancements were having an equatorial anomaly like structure having a minimum at the dip equator. Fesen et al. (1989) reported the prominent enhancement of $F$-region critical frequency in the ionization crest region during disturbed days. Sahai et al. (1990) also compared the variations of $F$-region parameters $\left(f_{o} F_{2}\right.$ and $\left.h^{\prime} F\right)$ with ground based observations of [OI] 777.4 $\mathrm{nm}, 630 \mathrm{~nm}$ and $557.7 \mathrm{~nm}$ from Cachoeira Paulista $\left(22.7^{\circ} \mathrm{S}\right.$, $\left.45.0^{\circ} \mathrm{W}\right)$, Brazil, a low latitude station and from Forteleza $\left(3.9^{\circ} \mathrm{S}, 38.4^{\circ} \mathrm{W}\right)$, Brazil, an equatorial station, during magnetic disturbances. They found the dynamic variations in the $F$-region ionospheric variations are well correlated with the non diurnal variations observed in the atomic oxygen airglow emissions at both equatorial and low latitudes.

\section{Seasonal Variation of $630 \mathrm{~nm}$ Nightglow Emis- sions}

We present and discuss the nocturnal seasonal variations of the [OI] $630 \mathrm{~nm}$ emission observed at Kolhapur, a station 
SEASONAL VARIATION OF AIRGLOW (OI 630nm) AT KOLHAPUR

(GEO LAT. $16.8^{\circ} \mathrm{N}$, LONG. $74.2^{\circ} \mathrm{E}$, DIP LAT. $10.6^{\circ} \mathrm{N}$ )
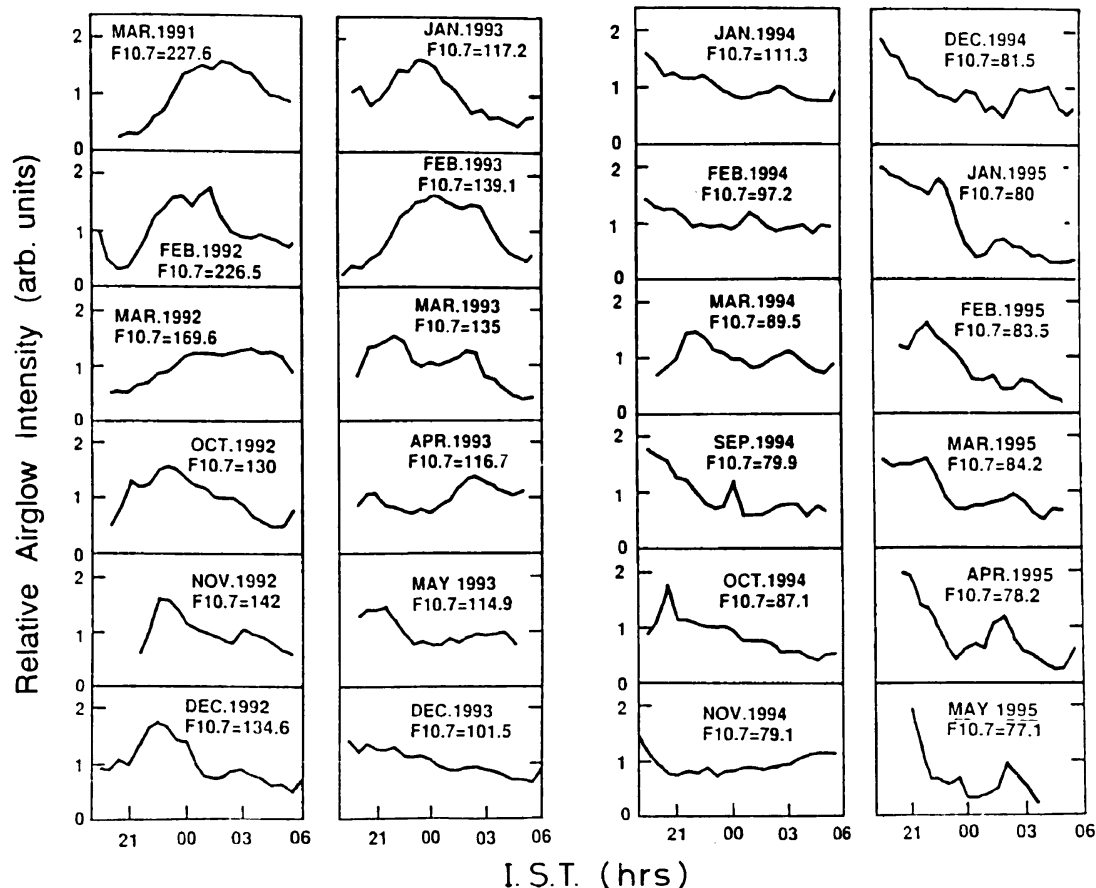

I. S.T. ( hrs)

Fig. 5. Seasonal variation of the monthly mean airglow $(630 \mathrm{~nm})$ intensity as a function of time (IST) on number of months observed at Kolhapur, the mean solar activity is also indicated in the Figure for the respective months by the monthly mean F10.7 cm flux values.

situated near equatorial anomaly region. The airglow data presented here are half hourly monthly mean values $(>8$ nights) from March 1991, 1992 to May 1995 which included the descending phase of the solar activity. The variations were calculated using half hourly values, normalised to the individual nocturnal mean values in order to show the relative amplitude and phase of the variations. Figure 5 shows the monthly mean relative nocturnal variations of $630 \mathrm{~nm}$ intensities during respective months. And the value of mean solar flux $(\mathrm{F} 10.7 \mathrm{~cm})$ during the months is also depicted respectively in the figures.

It is well known that $630 \mathrm{~nm}$ airglow intensity variation at a given place depends on solar activity (Sahai et al., 1988a, b). In particular the [OI] $630 \mathrm{~nm}$ emission at low latitudes results mainly due to dissociative recombination between $\mathrm{O}_{2}$ molecules and electrons. The observed ratios of neutral atmospheric parameters $\left(\mathrm{O}, \mathrm{N}_{2}, \mathrm{O}_{2}\right)$ and electron density for high solar activity and low solar activity, at low latitudes are higher, the observed $F$-region peak height changes also show that heights are lower during high solar activity as compared to low solar activity (Sahai et al., 1988a). Their observations also show that airglow intensity $(630 \mathrm{~nm})$ is proportional to solar F10.7 cm flux values.

In Fig. 5, we observe significant changes taking place in $630 \mathrm{~nm}$ intensity maximum from month to month with changes in solar activity. The intensity peaks appearing before midnight have been shifted to post midnight hours while moving from one month to another. This is clearly manifested in the months from December 1992 to April 1993. It is also noted that in the months of February 1992 and 1993 a small dip in intensity takes place around midnight and intensities are large, but with decrease in solar activity, the relative intensities are reduced in February 1994 and 1995. The peaks in intensities have occurred during October to December, 1992, before midnight (2200-2300 hrs IST). The intensity peaks are smaller in magnitude and less defined in the months having low solar flux values from December, 1993 onwards.

In Fig. 6(a) we plot in the upper panel the mean values of the airglow intensity $(630 \mathrm{~nm})$ at night during the months of December 1989, February and April 1990 — a period of high solar activity (average F10.7 cm flux $=192.0$ ) (Mukherjee and Dyson, 1992). This epoch consisted of the most active period of the solar cycle number 22 . The mean F10.7 $\mathrm{cm}$ fluxes for the respective months were 213.0, 178.0 and 185.0 units. For comparison we also plot in Fig. 6(b) the characteristic airglow variation at night during the months of December 1995 and January-April 1996 - a period of low solar activity (average F10.7 $\mathrm{cm}$ flux $=70.4$ ). As can be seen in the Figure, airglow peaks are sharp, well defined and enhanced during the periods of high solar activity in comparison to similar variation during the periods of low solar activity. The values of airglow intensity at a particular month are larger at high solar activity than at low solar activity.

\section{Conclusions}

On the basis of above discussion and observational evidence, the main features associated with the nightglow observations can be summarized as follows: 

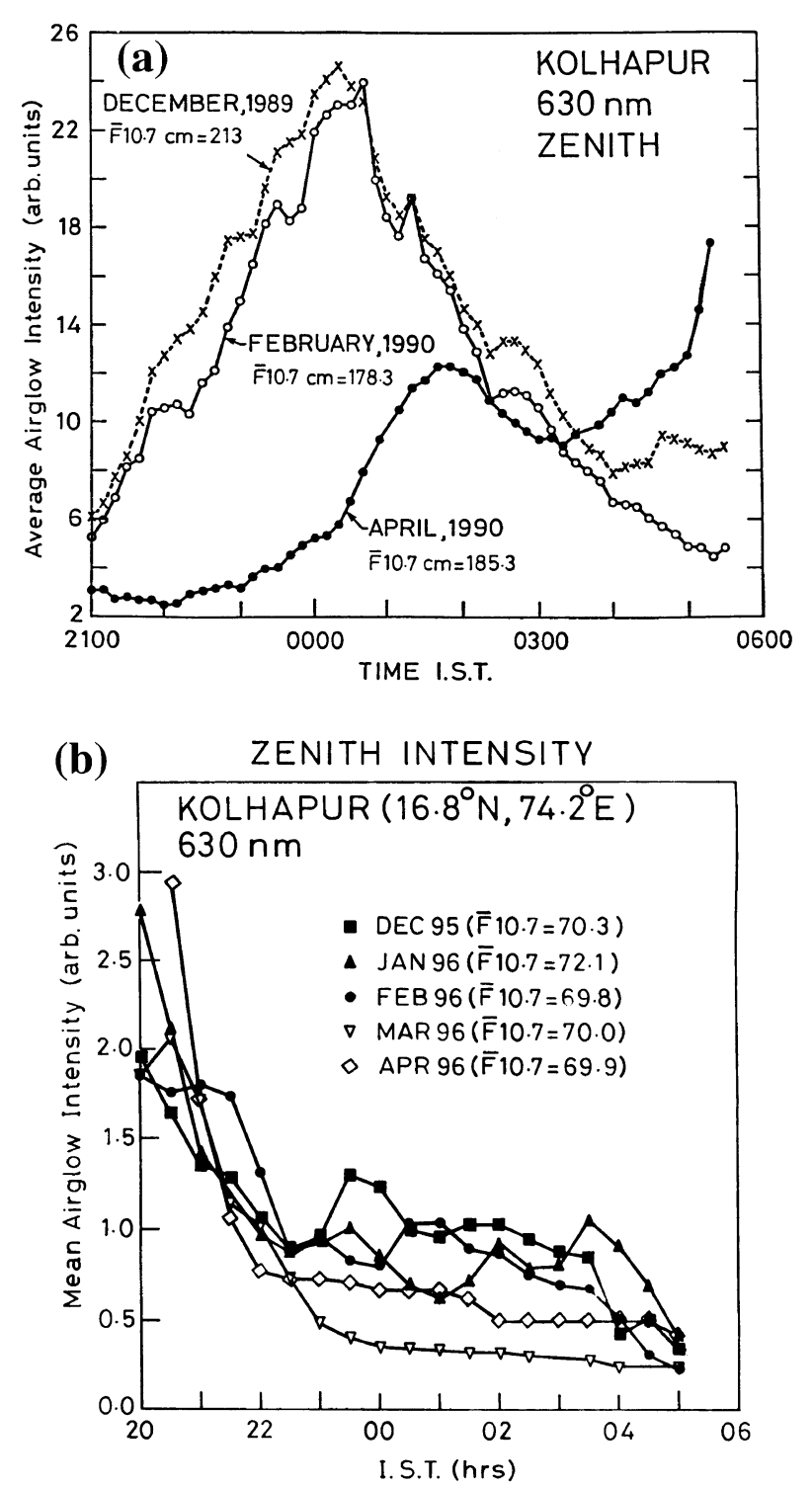

Fig. 6. (a) Mean nighttime variation of relative airglow intensity $(630 \mathrm{~nm})$ during December 1989, February and April 1990 observed at Kolhapur. (b) Same as Fig. 6(a) but for several months between December 1995 to April 1996.

i) On typical quiet $(\mathrm{Ap}<5)$ night condition the [OI] 630 $\mathrm{nm}$ nightglow variations at Kolhapur show good correlations with the variations of the electron density at the peak of the $F_{2}$ layer at Ahmedabad. However, with increase in magnetic disturbance, low latitude ionosphere undergoes rapid height variations. The height variations of the emitting $F_{2}$ layer produce the corresponding signature in observed nightglow in $630 \mathrm{~nm}$. Such occurence of double maxima in $630 \mathrm{~nm}$ in association of intense magnetic disturbances is common at the station. The ionospheric height variations could be due to large-scale travelling ionospheric disturbances (TIDs) with periods about 3 hours which occur at the auroral region during intense magnetic storm. TIDs are wavelike variations of densities of the $F$ layer and take the form of acoustic-gravity waves or compress waves where maxima are created by the sudden abnormal lowering of $h^{\prime} F$, which causes intensity increase of the red line occuring suddenly around midnight and shape of a pulse wave or a solitary wave. It should be made clear here that the airglow intensity variation (or electron density variation) is not always drift with background plasma motion, but could have a large phase velocity relative to background wind. The former is the case of a plasma bubble and the latter case is a TID. But so far very few studies on $F$-region gravity waves have been done utilizing airglow data (Sobral et al., 1997; Mendillo et al., 1997; Mende et al., 1998). Misawa et al. (1984) reported simultaneous enhancements of the zenith [OI] $630.0 \mathrm{~nm}$ and [OI] $557.7 \mathrm{~nm}$ intensities at Yokosuka $\left(35^{\circ} 15^{\prime} \mathrm{N}, 139^{\circ} 44^{\prime} \mathrm{E}\right)$ during auroral substorms. TIDs are divided into medium scale and large scale TIDs. The medium scale TIDs exist in periods between 10 to 60 minutes and they display poor correlation with magnetic activity while the large scale TIDs with periods between 30 to 120 minutes show positive correlation with magnetic activity (Misawa and Takeuchi, 1982). Misawa et al. (1984) suggested that the large scale TIDs and intensities of the red line $(630 \mathrm{~nm})$ emission are caused by the same large scale atmospheric gravity waves triggered by severe magnetospheric substorms. The double maximum seem to be direct evidence of Testud's theory which is generally interpreted as a succession of two positive impulses (Misawa et al., 1984).

ii) The seasonal variation of $630 \mathrm{~nm}$ intensity at the station shows the characteristic features dependent on solar activity (Sahai et al., 1988a, b). Although there was variability in the $630 \mathrm{~nm}$ intensity during the night, no significant regular pattern could be noticed. The mean seasonal nocturnal variations in [OI] $630 \mathrm{~nm}$ show the presence of pre and post midnight enhancements. The post midnight enhancements in $630 \mathrm{~nm}$ could be due to the passage of poleward winds caused due to equatorial Midnight Temperature Maximum (MTM) (Rao and Sastri, 1994). The enhancement of 630 $\mathrm{nm}$ emission after midnight has been explained due to the equatorial temperature maximum often observed at the $F$ region height which is accompanied by a density maximum producing the equatorial midnight pressure bulge. The situation manifests itself due to a three dimensional circulation system in which the midnight sector of the equatorial thermosphere below $200 \mathrm{~km}$ is heated due to compressive flow driven by the solar heating on the dayside side (Dickinson et al., 1975; Roble et al., 1982). This type of circulation produces a localized temperature maximum with a density minimum below $200 \mathrm{~km}$. There are vertical upward and downward motions, the upward motion transports heat and energy giving rise to MTM and pressure bulge. The equatorial midnight pressure bulge controls the nighttime neutral wind.

Acknowledgments. The airglow measurements are carried out under the scientific collaboration between IIG, Mumbai and Shivaji University, Kolhapur. The three photometers were provided by Prof. P. L. Dyson, La Trobe University, Melbourne, Australia, under Indo-Australia agreement on Science and Technology. The funds for research on studies of the upper atmosphere in IIG are provided by Department of Science and Technology (DST), Govt. of India, New Delhi. The authors are thankful to Prof. H. Chandra, Physical Research Laboratory, Ahmedabad, for supplying the ionosonde data. 


\section{References}

Dickinson, R. E., E. C. Reddy, and R. G. Roble, Meridional circulation in the thermosphere 1. Equinox condition, J. Atmos. Sci., 32, 1737-1747, 1975.

Fesen, C. G., G. Crowley, and R. G. Roble, Ionospheric effects at low latitudes during March 22, 1979, Geomagnetic storm, J. Geophys. Res., 94, 5405-5417, 1989.

Mende, S. B., H. U. Frey, S. P. Geller, and G. R. Swenson, Gravity wave modulated Airglow Observation from Space Craft, Geophys. Res. Lett., 25, 757-760, 1998.

Mendillo, M., J. Baumgardner, D. Nottingham, J. Aarons, B. Reinisch, J. Scali, and M. Kelly, Investigations of thermospheric-ionospheric dynamics with $6300 \AA$ images from the Arecibo Observatory, J. Geophys. Res., 102, 7331-7342, 1997.

Misawa, K. and I. Takeuchi, Magnetic activity and quasi-periodic variations of intensity of the oxygen green and red lines, J. Atmos. Terr. Phys., 44(2), 179-182, 1982.

Misawa, K. and I. Takeuchi, Simultaneous observations of progressive intensifications of the oxygen red line in the four cardinal directions, $J$. Atmos. Terr. Phys., 46, 105-108, 1984.

Misawa, K., I. Takeuchi, Y. Kato, and I. Aoyama, Generation of Intensity covariations of the Oxygen green and red lines in the nightglow, Ann. Geophys., 2(1), 77-82, 1984.

Moore, J. G. and E. J. Weber, OI $6300 \AA$ Å airglow measurements of equatorial plasma depletions, J. Atmos. Terr. Phys., 43, 851-858, 1981.

Mukherjee, G. K. and P. L. Dyson, A filter tilting photometer for nightglow measurements of $630.0 \mathrm{~nm}$ emission line, Ind. J. Radio and Space Phys., 21, 212-218, 1992.

Rao, H. N. R. and J. H. Sastri, Characteristics of the equatorial midnight temperature maximum in the Indian Sector, Ann. Geophys., 12, 276-278, 1994.

Rishbeth, H., R. Gordon, D. Rees, and T. J. Fuller-Rowell, Modelling of thermospheric composition changes caused by a severe magnetic storm, Planet. Space Sci., 33, 1283-1301, 1985.

Roble, R. G., R. E. Dickinson, and E. C. Ridley, Global circulation and temperature structure of the thermosphere with high latitude plasma convection, J. Geophys. Res., 87, 1599-1606, 1982.

Sahai, Y., H. Takahashi, J. A. Bittencourt, J. H. A. Sobral, and N. R. Teixeira, Solar and Seasonal variations of the low latitude OI $630 \mathrm{~nm}$ nightglow, J. Atmos. Terr. Phys., 50(2), 135-140, 1988a.

Sahai, Y., J. A. Bittencourt, H. Takahashi, N. R. Teixeira, J. H. A. Sobral, B. A. Tinsley, and R. P. Rohrbaugh, Multispectral optical observations of ionospheric $F$-region storm effects at low latitude, Planet. Space Sci. 36(4), 371-381, 1988b.

Sahai, Y., J. A. Bittencourt, H. Takahashi, N. R. Teixeira, B. A. Tinsley, and R. P. Rohrbaugh, Analysis of storm-time low-latitude simultaneous ionosphere and nightglow emission measurements, J. Atmos. Terr. Phys., 52, 749-757, 1990.

Sobral, J. H. A., G. L. Borba, M. A. Abdu, I. S. Batista, H. Sawant, C. J. Zamlutti, H. Takahashi, and Y. Nakamura, Post-sunset winter time 630.0 nm airglow perturbations associated with gravity waves at low latitudes in the South American Sector, J. Atmos. Solar Terr. Phys., 59, 1611-1623, 1997.

Takahashi, T., H. Oya, and S. Watanabe, Ionospheric disturbances induced by storm associated electric fields in the low latitude $F$-region, J. Geomag. Geoelectr., 39, 187-209, 1987.

Vanzandt, T. E. and V. L. Peterson, Detailed maps of tropical $6300 \AA$ nightglow enhancements and their implications on the ionospheric $F_{2}$ layer, Ann. Geophys., 24, 747-759, 1968.

G. K. Mukherjee (e-mail: gkm@iig.iigm.res.in), L. Carlo, and S. H. Mahajan 